\title{
THE ROOTS OF ISLAMOPHOBIA IN CONTEMPORARY EUROPE. THE RESULTS OF AN EMPIRICAL RESEARCH
}

\author{
Osman KOMURCU \\ National University of Political Studies and Public Administration \\ Bucharest/Romania \\ komurcuosman@gmail.com
}

\begin{abstract}
Multiculturalism is a term that encompasses the variety of policy responses promoted by democratic governments all over the world in order to address one of the main issues derived from a phenomenon that has characterized the $20^{\text {th }}$ century and the beginning of the $21^{\text {st }}$ century: globalization. This phenomenon has had many secondary effects, the increased migratory trends being the effect addressed by multiculturalist policies. The larger number of migrants who have taken advantage of the faster and cheaper transportation available to the average citizen has put pressure on the host societies, which had to find solutions in order to accommodate the large migratory influxes. Multiculturalism has proven to be a successful policy in several countries, but in the past three decades the efficiency of multiculturalist policies has been questioned with the rise of currents that deny diversity (xenophobia, racism or Islamophobia). Being the newest current that opposes multiculturalism, Islamophobia is a concept that is placed in the center of this article, an article that not only tries to define the new tendencies represented by Islamophobic views, but also to identify how these tendencies are reflected in the European Union. A semi-structured interview and a questionnaire were the instruments used in order to collect the data needed for identifying how multiculturalism and Islamophobia manifest themselves, the results showing that most of the EU countries foster integration of Muslim immigrants. However, some countries have a much larger Muslim community than others, which, in turn, generates
\end{abstract}


more problems like ghettoization or the higher intensity of Islamophobic tendencies. These results allow in the end of the article the drawing of several conclusions regarding the way multiculturalism and Islamophobia manifest in the EU and the proposal of several policy recommendations that could be implemented by authorities in order to combat the rising issues generated by the Islamophobia current.

\section{Keywords}

Diversity; Islamophobia; multiculturalism; public policies

\section{INTRODUCTION}

One of the main phenomena of the past decades is the phenomenon known as 'globalization', which has deeply influenced the modern social and economic life. Globalization has many facets and one of them consists of the rising migratory trends favored by the faster and cheaper transportation systems and by the faster and cheaper communication means that are available today to large masses of people. In turn, the rising migratory trends have generated several secondary effects, one of these effects being the need for host countries to find ways to better accommodate the large masses of immigrants. When faced with these new problems, many host countries have responded by adopting policies that can be framed under a new current that can be called 'multiculturalism' (Komurcu 2019).

Multiculturalism has been a widely used policy response in states characterized by high migratory influxes because it has been proved to be successful in most of the countries where it was used (e.g. Canada, United Kingdom, Australia), favoring the integration of migrants and a better relation between migrants, on one hand, and the host society, on the other hand. However, during the 1990s things began to change, when different phenomena that aimed at denying multiculturalism began to take shape in the host countries. This was the time when currents like antisemitism, racism or xenophobia began to attract more followers and new phenomena denying multiculturalism began to take shape. 
In this category of new phenomena can be included a concept that is fundamental to this article, the Islamophobia case.

What began as a current supported by only a few partisans, Islamophobia became in less than three decades a social phenomenon present in almost all Western cultures. Favored by events like the 9/11 attacks in the United States of America or the numerous terrorist attacks that took place on the territory of the European Union in the past decade, attacks that have been associated with Muslim fundamentalists, Islamophobia has rapidly became a widespread current in the Western society and added to the already numerous forms of multiculturalism's denial that were already present in cultures with large migrant influxes.

These are the premises that form the basic assumptions of this article, an article that aims at constructing an image of the current situation arising from the clash of two opposing currents: multiculturalism and Islamophobia. The effects of this clash will be analysed with reference to the situation in the EU as a whole and especially with reference to the specific situation in two of the EU countries: Romania and the United Kingdom. This approach will allow to make comparisons between the way multiculturalism and Islamophobia manifest themselves and the way they are perceived and affect societies that are known for their long history of large migratory influxes (the British society, for example) and that are closer to the geographical Islamic space, but that have not been characterized by large waves of immigrants in the past decades (the Romanian society, for example). The analysis of the situation regarding multiculturalism and Islamophobia in the EU is relevant not only because of the differences between different countries regarding the flow of immigrants, but also due to the fact that each EU country has its own specificity pertaining to elements like the experience in adopting multiculturalist values, the economic situation, the dimensions of the Muslim communities or the frequency of the terrorist attacks. The study that will be performed will help draw some relevant conclusions regarding the different manifestations of multiculturalism and Islamophobia in the EU and will help formulate policy recommendations that can be implemented in the future. 


\section{THEORETICAL FRAMEWORK}

The theoretical foundation of this paper consists of two core concepts: 'multiculturalism' and 'Islamophobia'. The first of these concepts, 'multiculturalism', has been widely studied in the literature in relation to the concept of culture by Modood (2005), Hofstede (1980) or Salat (2001). These definitions represent the foundation on which the complex concept of multiculturalism can be constructed.

Starting from the definitions of culture, scholars have tried to define multiculturalism, one of the most important definitions being the one provided by Kymlicka (2012), who argues that multiculturalism is merely the political and legal accommodation of ethnic diversity. In order to create a complete framework regarding the concept of multiculturalism, we do not have to confine ourselves to Kymlicka's approach and to present views of this concept that are supported by other scholars:

- Kukathas (2004) considers multiculturalism as an approach aiming at fully eliminating racism and at nurturing differences between minorities and the majority group of the host country;

- Frunza (2010) defines multiculturalism as a concept strongly associated with 'autonomy', which is not only accepted, but also promoted by multiculturalism as long as it offers the minority groups a chance to conserve their identity and better chances to integrate in the wider society;

- Bloemraad and Wright (2014) argue that, in order to fully understand multiculturalism, we have to refer to concepts that are specific to domains like demography, public policy, political philosophy or public discourse;

- Bastian (2012) considers that multiculturalism is a concept that can be described not only in the context of the values promoted by demographic pluralism, but it also has to take into consideration the larger and more complex issues pertaining to diversity in all its forms (religious, ethnic and racial).

All these views of multiculturalism show that this concept does not have a widely accepted definition and that it can only be understood through the lens of various sciences (sociology or political philosophy, for example) and in relation with other concepts (racism, autonomy, demography etc.). The 
complexity of multiculturalist policies can be better understood if we refer to the multitude of public policies devoted to multiculturalism that were implemented in different EU countries where multiculturalism has been intensely promoted in the past few decades. In these countries, multiculturalism was developed through a set of public policies based on four pillars:

1. Education. An example is Germany, where children from minority groups learn between two and five hours a day about values pertaining to cultural diversity (Issa 2013).

2. Housing. An example is Finland, where a strategy named 'Socially Sustainable Finland 2020' was adopted, a document aimed at decreasing the costs of housing, so that the minimum housing conditions would be afforded by migrant families (Housing Europe 2015).

3. Cultural policies. An example is The Czech Republic, where several policies regarding the better integration of the Roma minority into the labour market were adopted at the governmental level. These policies were constructed around a better access of Roma children to primary education and university education through programs that helped them finish their studies and become employed on the labour market (Sirovatka 2011).

4. Migration policies. Not all EU countries have paid the same level of attention to policies aimed at including migrants. According to the Migration Policy Index, there are large differences between Western EU countries, that have a longer experience in integrating migrants (Sweden, Finland, Belgium, Germany etc.), and the Central and Eastern European Countries, that seem not to accept diversity in the same manner as Western democracies accept diversity (Triandafyllidou 2012).

These four pillars show that multiculturalism is not a complex concept only from a terminological perspective, but also from a practical perspective, since true multiculturalist policies have to take into consideration the multitude of social, economic and political aspects that influence the relation between migrants who represent minority groups and the larger group represented by the natives of the host society.

The second part of the theoretical foundation of this article consists of the framework that defines 'Islamophobia'. This is a concept that appeared in the 
last decades of the $20^{\text {th }}$ century as a political construct used to identify the intensity, causes, consequences, presence, history and dimensions of sentiments against Muslims and Islamic adherents (Bleich 2012). In a broad sense, Islamophobia refers to the all acts of hostility or fear directed towards Islamic adherents, acts that manifest themselves through several stereotypical perceptions of non-Muslims regarding Muslims (stereotypes like the inferiority of the Islamic religion, the more violent and irrational behaviour of Islamic adherents etc.) (Alshammari 2013).

Both Bleich's and Alshammari's perspectives on Islamophobia reflect the clash that appears between this current and the multiculturalist view of a society. This clash is best reflected on the territory of the European Union, where multiculturalism has become in the past decades an important pillar of public discourse, but also where Islamophobia manifests itself in a variety of ways: through terrorist attacks against Muslims, through attacks on Muslim religious infrastructure, through an increased hatred against Muslims and even through attempts of legalizing Islamophobia (Bayrakli and Hafez 2018). These instances of Islamophobia represent a threat not only for the multicultural European Union, but also for the image of the EU as a tolerant organism in relation to ethnic minorities and for the internal security of the Union, since it undermines its ideals of peace and coexistence.

\section{METHODOLOGY}

The theoretical framework has shown that the clash between multiculturalism and Islamophobia may represent a threat to many widely accepted values in the European Union (peace, tolerance, coexistence etc.). For this reason, it is important to study how multiculturalism and Islamophobia manifest themselves, how they interact and what effects they have in society. We will study the relation between multiculturalism and Islamophobia in the EU as a whole, with emphasis on the particular case of Romania and the United Kingdom, for which an empirical research was made. The study not only seeks 
to identify traits related to multiculturalism and Islamophobia in the European Union, but also to attain several specific objectives:

- to determine how Muslims have succeeded in adapting to the specific way of life of Europeans;

- to determine why Muslims have decided to emigrate from their countries of origin to the EU;

- to determine what is the Muslims' perception on the way Europeans people live;

- to compare how Muslims perceive the Islamophobia current in relation to how this current is perceived by Europeans.

Two instruments were used in order to collect the data needed in order to attain these specific objectives: an interview and a questionnaire. Both the interview and the questionnaire were constructed around a set of key variables that can be grouped into four main categories: variables that reflect the integration profoundness of immigrants originating from Muslim countries, variables that reflect the perception of these immigrants regarding the culture in their host countries, variables that reflect the attitude of Europeans in relation to Muslim migrants and variables that reflect the respondents' perception regarding Islamophobia.

There were 15 participants that have responded to the interview questions and 200 participants that have taken the questionnaire. The interview sample consisted of five Muslim immigrants who currently live in the UK and ten Muslim immigrants who currently live in Romania, while the questionnaire sample consisted of 150 residents in the UK and 50 residents in Romania. Approximately half of the 200 participants during the questionnaire stage of the study were born either in Romania or the UK from Romanian or British parents, but the sample also consisted of participants who are in one of the following situations: are born in Romania/UK from immigrant parents, are born in Romania/UK from parents of different nationalities or have immigrated to Romania/UK. The diversity of the sample is determined not only by respondents' social status (immigrants or natives), but also by the multitude of countries of origin. As shown previously, most respondents are Romanian/British nationals, but the sample also consisted of immigrants 
originating from a variety of Muslim countries (mostly Turkey, but also countries like Nigeria, Syria, Saudi Arabia, Lebanon or Turkmenistan).

\section{RESULTS}

The results obtained can be systematized in relation to the set of four objectives pursued in the study:

1. Determining how Muslims have succeeded in adapting to the specific way of life of Europeans

One way of determining the degree to which Muslims have adapted to their new social environments is that of identifying the level of understanding between people from the Muslim communities, on one hand, and people from the host societies, on the other hand. A study that has sought to make this comparison was synthesized in a report written by the Open Society Institute with reference to the specific situation encountered in 11 large cities in several EU countries: London, Leicester, Stockholm, Copenhagen, Berlin, Hamburg, Amsterdam, Rotterdam, Antwerp, Paris and Marseille (Open Society Institute 2011). When the non-Muslims in these cities were asked if they agreed with the statement that Muslims immigrants living in their neighborhood share the same values as the community of people who were born there, over $50 \%$ have disagreed or strongly disagreed. 


\section{How strongly do you agree with the statement 'Muslims in this neighborhood share the same values as the general population'?}

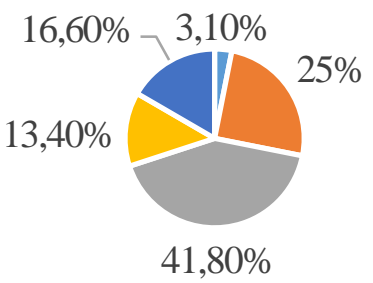

\section{- Strongly agree - Agree $\quad$ Disagree \\ - Strongly disagree • Don't know}

Figure 1. Muslims' level of adaptation to the specific way of life of Europeans Source: Open Society Institute (2011)

The data in Figure 1 shows that most Europeans do not think that Muslims have succeeded in adopting the specific values of the EU and, as a result, in adapting to the European specific way of life. However, there is a significant number of EU citizens living in one of the 11 cities that have been part of the Open Society Institute's study who believe that Muslims have begun to share the same values as their neighbors and thus have managed to adapt to their new social environment (almost $30 \%$ of the participants agreed or strongly agreed with the statement 'Muslims in this neighborhood share the same values as the general population').

These results are supported by the empirical research made in two EU countries, Romania and the UK, research that has shown that most of the Muslims who currently live in these two states have succeeded in part in their attempt to adapt to the way of life of the natives. Most of them currently have a good or very good understanding of Romanian/English and appreciate the intrinsic qualities of Romanian/British people, characterizing them as 'intelligent', 'communicative' and 'well intended'. 


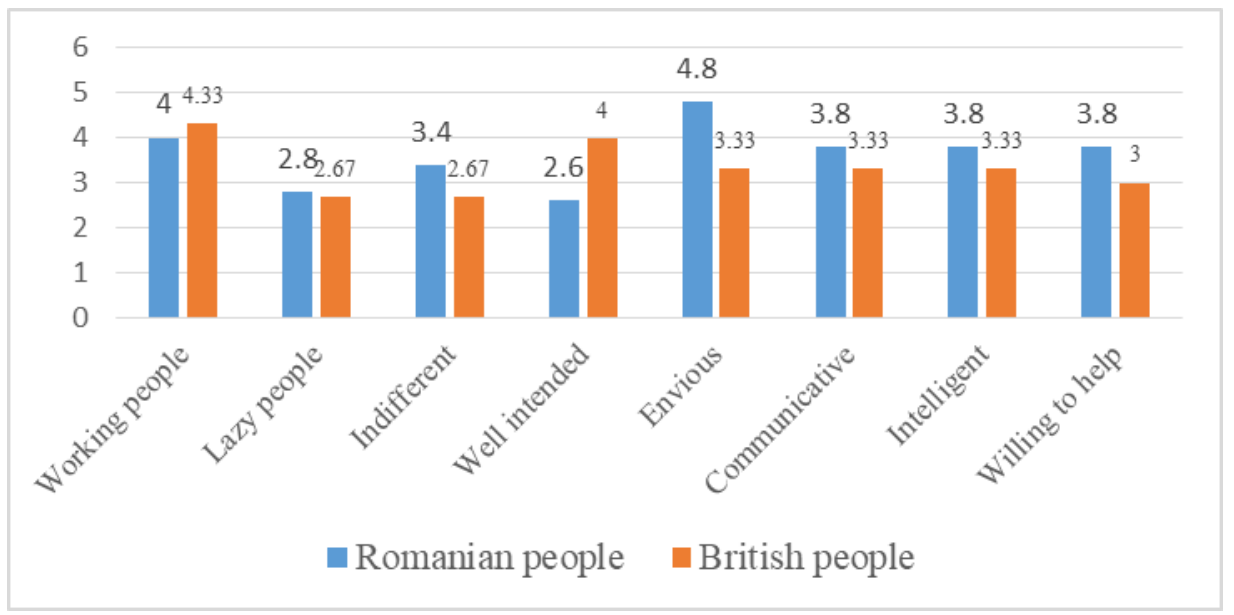

Figure 2. Average scores that reflect how Muslim immigrants perceive the of Romanian or British people

Source: Komurcu (2019)

Although the process of adaptation to the local culture is successful for most of the respondents, this is not the case for all the respondents, showing there are still many immigrants who have not yet succeeded in adapting to the Romanian/British way of life. These are, in general, the people who tend to isolate themselves in a process called 'ghettoization' (Wieviorka 1991) and are more inclined to be influenced by radical Islamic movements (Turner 2015). As the results of the study have shown, this process of ghettoization is more intense in the UK than in Romania.

2. Determining why Muslims have decided to emigrate from their countries of origin to the EU

When referring to the recent wave of Muslim migration, that took place between 2010 and 2016, Tausch (2019) has highlighted the fact that approximately on third the 3.7 million Muslims who have settled in an EU Member State during this period have been granted refugee status, being displaced from their countries of origin by political or economic factors. 


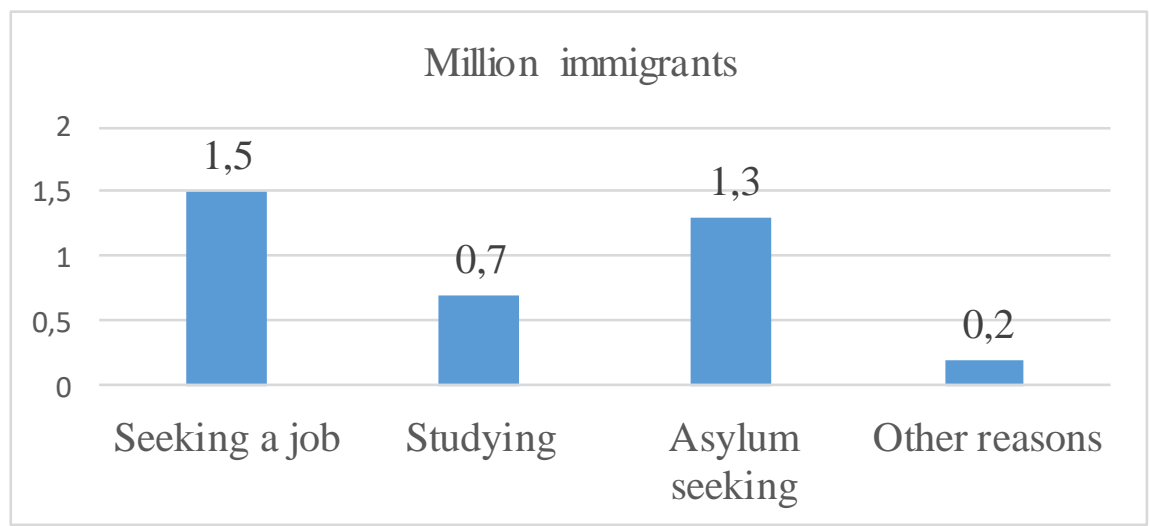

Figure 3. Reasons for Muslims' migration between 2010 and 2016

Source: Tausch (2019)

In the case of the empirical research made with reference to Muslims living in the UK or Romania, the main reason for immigration was not seeking a job, but education, since 5 of the respondents to the interview have stated that they came to Romania or the UK because they wanted to attend a particular school or university and only 3 of the respondents came to Romania or the UK in search of a job opportunity.

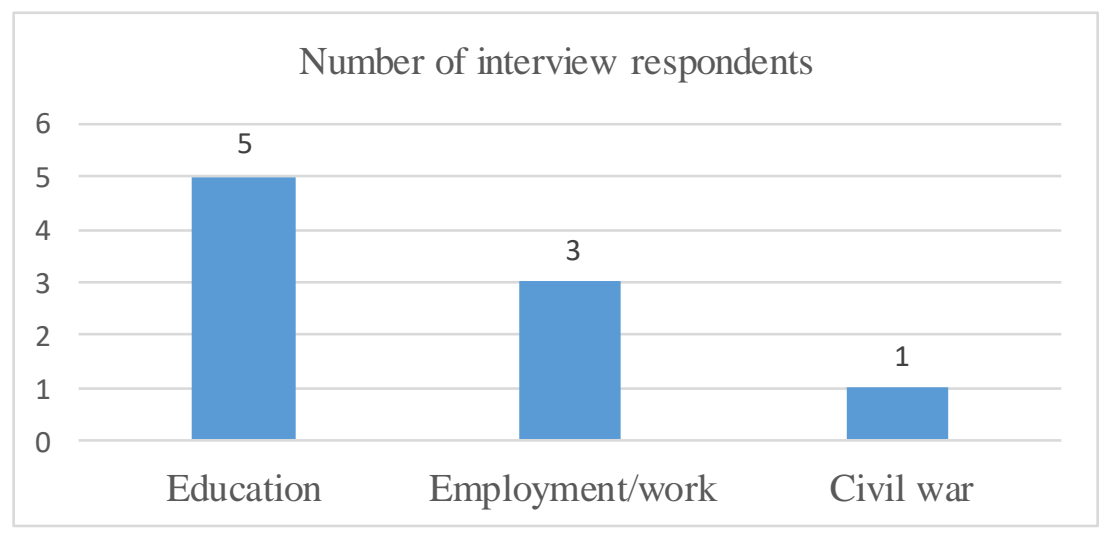

Figure 4. Reasons for Muslims' migration according to the empirical research Source: Котигси (2019) 
The results obtained during the questionnaire phase of the empirical research have shown that the main reason for immigration is different in the case of immigrants in Romania than in the case of immigrants in the United Kingdom. While Muslims currently living in Romania have immigrated mainly because they wanted to reunite with their families, Muslims currently living in the UK have immigrated mainly because they were seeking a better educational system. The different reasons for migration have to be taken into consideration when developing policies aimed at reducing the negative impact of Islamophobia in Romania or the UK.

Both the statistical results referring to the situation of Muslim migration to the European Union as a whole and the specific empirical results referring to the situation of Muslim migration to Romania and the UK have shown that the two main reasons for Muslim immigration are that of seeking employment and obtaining an educational degree.

3. Determining what is the Muslims' perception on the way Europeans live The nature of Muslims' perception regarding the Europeans' way of life can be indirectly quantified by determining whether Muslims living in EU's Member States have a feeling of attachment to these countries. A study in this regard was made by the European Union Agency for Fundamental Rights (2017), an organization that has developed a survey asking Muslims living in several EU countries how attached did they feel to their host country. The level of attachment was measured on a scale from 1 to 5 , the following results being obtained: 


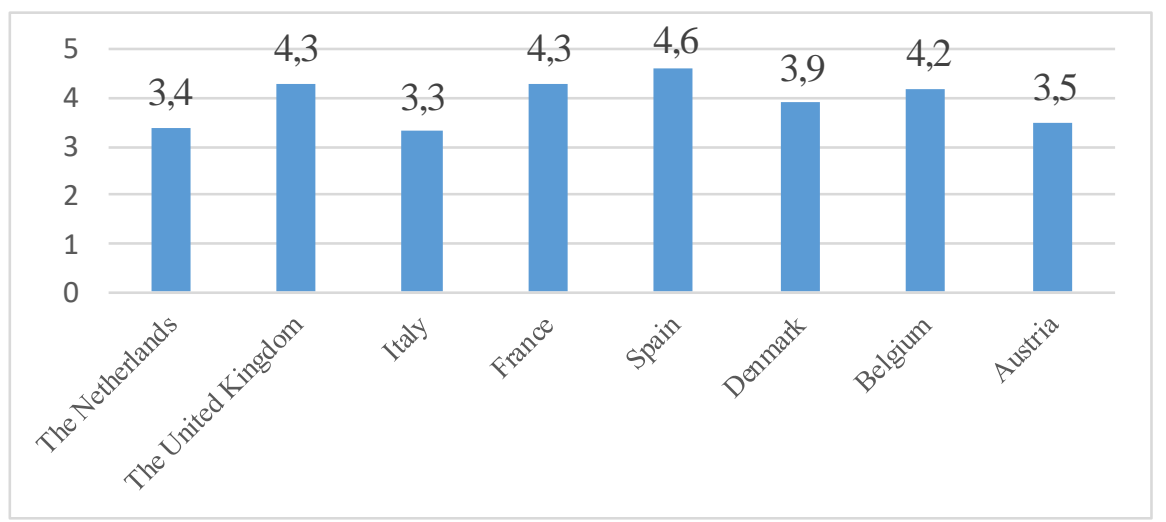

Figure 5. Synthetic scores showing Muslims' level of attachment to their host countries

Source: European Union Agency for Fundamental Rights (2017)

These results show that Muslims have a good perception on the way Europeans live, the most attached Muslim immigrants to their new societies being the ones living in Spain, the United Kingdom and Belgium.

These results have been confirmed by the empirical research made on the particular case of the UK and Romania. Most of the respondents have shown that they have a good perception regarding the way of life of the people from the local cultures that have adopted them. This is both the case of Romania (where over $70 \%$ of respondents have declared that they felt close or very close to the society that has adopted them) and the UK (where $50 \%$ of the respondents have manifested a high degree of closeness in relation to their host society). The positive perception of Muslims regarding the countries they have emigrated to indirectly reflects a good perception regarding how Europeans live, but also that the conditions for a smooth adaptation to a new life are met. 


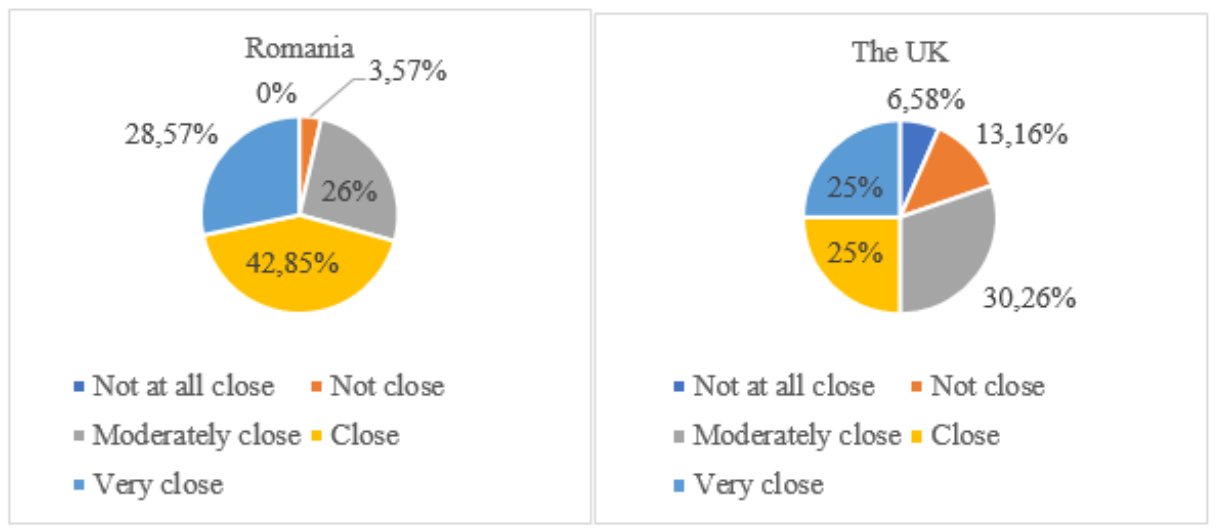

Figure 6. Muslims' living in Romania and the UK responses to the question 'How close do you feel towards the country you now live in?' Source: Komurcu (2019)

This positive perception was also reflected by the respondents' lack of preference when asked whether they would like to live in a neighborhood mostly made up of Muslims or of natives (Komurcu 2019). This strengthens the fact that the process of immigrants' adaptation to their new social environment runs under optimal conditions.

4. Comparing how Muslims perceive the Islamophobia current in relation to how this current is perceived by Europeans

Statistics show that a relatively high number of Muslims experience at least one act of discrimination over a period of time of one year (European Network Against Racism, 2017). 


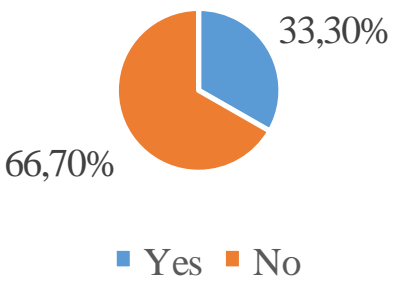

Figure 7. Muslims' responses to the question 'Have you experienced discrimination in the past 12 months?'

Source: European Network Against Racism (2017)

These trends are supported by the results obtained during the empirical research, which has shown that the severity of the Islamophobia current is perceived as being relatively high both in the UK and in Romania, but especially in Great Britain.

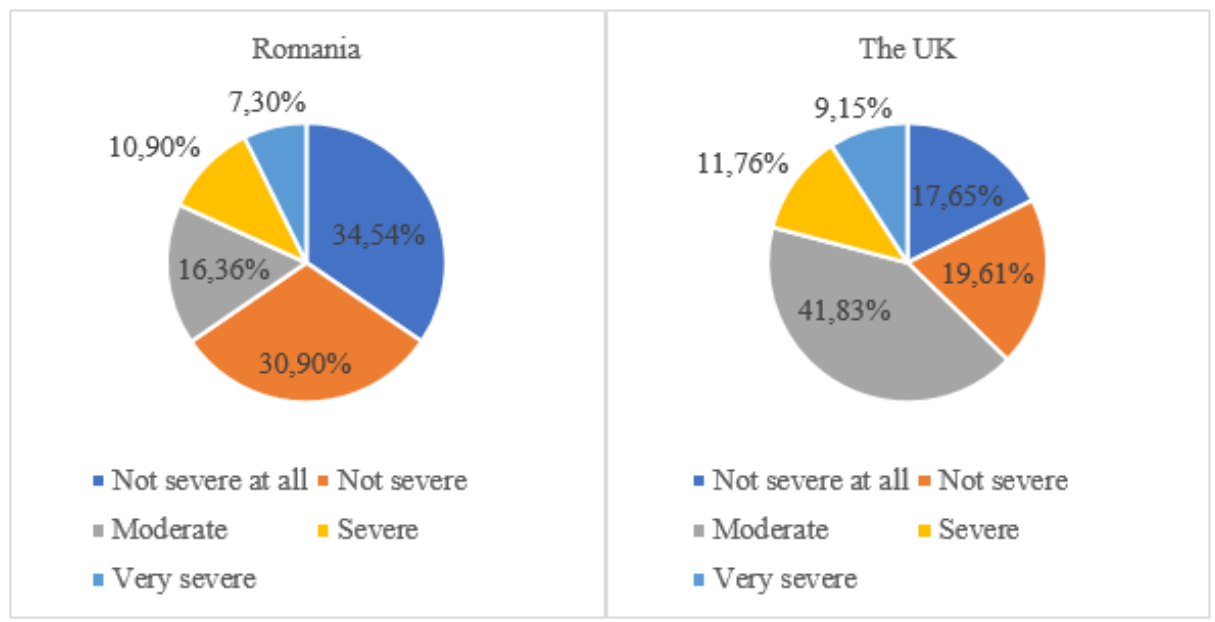

Figure 8. The perception of British/Romanian residents in relation to the intensity of Islamophobia in their country

Source: Komurcu (2019) 
Both Romanian and British people believe that the main reason Islamophobia became such an important issue is represented by the 9/11 attacks, but important reasons for the rise of Islamophobia are also the numerous terrorist attacks on the EU territory or the migrant crisis. The residents of Romania and Great Britain not only agree to the reasons of the rise of Islamophobia, but also to the main possible actions that could be taken against this trend: a better education of non-Muslims regarding Islamic culture, a stricter regulation against Islamic discrimination and better implemented government policies (Komurcu 2019).

Other important results obtained during the empirical research are the following (Komurcu 2019):

- most of the Muslim respondents think their rights and freedoms are respected in Europe;

- British nationals tend to interact more frequently with Muslims living in the UK than Romanians tend to interact with Muslims living in Romania;

- there is no consensus between respondents regarding whether their country should receive Muslim migrants;

- the British nationals are more open towards relationships with Muslim immigrants than Romanian nationals (they do not disagree with Muslims being in their neighborhoods, they would like to have more Muslim contacts in order to better understand the Islamic culture and are more reluctant toward the public discourse of parties that are recognized for their anti-Islamic views). The fact that Romanians are less open towards relationships with Muslim immigrants reflects indirectly in the higher tendency of Romanian nationals of associating stereotypes with Muslims and of agreeing with statements like 'Islam teaches its followers to oppress women' or 'Muslims' religion is primitive and barbaric'.

All these results show that the situation in many European states can be considered as being similar from many perspectives when debating the Islamophobia case, but also that the situation in the each country is a specific one from other perspectives, suggesting that the approach in promoting multiculturalism and in diminishing the negative effects of Islamophobia should be different from country to country. 


\section{CONCLUSIONS AND POLICY RECOMMENDATIONS}

There are several important conclusions that can be drawn based on the results obtained and several policy recommendations that could be made in relation to these conclusions:

1. The Muslims' specific way of life is not familiar for most Europeans The lack of information generates barriers between natives and Muslim immigrants. In order to break down these barriers, policies that seek to promote communication between different cultures can be implemented. These policies could be aimed especially at facilitating interaction between children of Muslim origin and European children, since cultural barriers often do not exist at young ages and multicultural values could be more easily assimilated by children than by adults who already have formed stereotypical views regarding Muslims and their way of life.

2. There are differences between the way nationals from different EU countries perceive their relation with Muslim immigrants

The results have shown that Romanians tend to be more reluctant when talking about forming relationships with Muslims than the British nationals are when talking about the same subject. These results can be explained by the fact that the Muslim community is much larger in some EU countries than others (for example, the Muslim community in Great Britain is more consistent than in Romania), thus the interaction between immigrants and natives being more frequent in some EU societies than others. Policies that could be implemented by European authorities in order to address these issues may refer to measures aimed at fostering the active participation of Muslims in cultural and social activities of Europeans.

3. The rise of Islamophobia can be mainly attributed to mass-media Most of the respondents that have participated in the empirical research have agreed that mass-media has played a crucial role in the past decades in enhancing Europeans' fear of Muslims. The extensive broadcasts of televisions in the days following major terrorist attacks and the proliferation of Muslim stereotypes in the written press have contributed to the rise of Islamophobia, a trend that can be reversed through policies aimed at enforcing stricter ethical 
codes of conduit for journalists and at offering more competences to authorities responsible with overseeing mass-media. For example, a measure that could be taken is that of allowing CNA, the audiovisual committee of Romania, to develop projects along with other Romanian authorities (e.g. the institutions responsible with combating discrimination).

4. The phenomenon of ghettoization is present in the large urban areas of several European cities

Muslim ghettoization is not yet present in countries like Romania, but in countries like the UK, Germany, Belgium or France, where the Muslim communities are consistent, it constitutes an important social issue. In order to tackle this problem, authorities may adopt policies aimed at improving the access of ethnic minorities to houses located in neighborhoods mostly occupied by natives and at improving the living conditions in the already formed Muslim neighborhoods. The conditions could be improved through measures based on investments that would allow good teachers to teach in schools located in neighborhoods mostly occupied by Muslims or through investments that would allow building new playgrounds for children or improving Muslims' access to the local work market.

These results represent key future directions that authorities in the EU could follow in order to reverse the trend of the rising Islamophobia and to promote the multiculturalist values. Before applying the policy measures proposed above, the authorities have to conduct more complex studies that address the limits of this research. One limit is that represented by the low sample of respondents who have participated, in order to draw more relevant conclusions studies with more participants and more representative samples for the entire population of the EU being required. Another limit that has to be addressed before implementing the policies proposed in this article is that derived from the fact that the study was performed in only two EU countries, Romania and the UK. This means that the policies proposed may not be equally efficient in other Member States where the situation regarding multiculturalism and Islamophobia may be different.

Despite these limits, the study has shown that multiculturalism can not be considered as being a simple abstract concept, but should be considered as a 
viable option of response for one of the most severe manifestations of hatred the European society has encountered in the past decades: Islamophobia. As a result, it can be said that multiculturalism still remains an instrument that can be used by governments and legislative bodies of the EU Member States in order to tackle the specific problems caused by migration, to ensure a better integration of migrants in the host societies and to diminish the negative effects of challenges against diversity like racism, xenophobia, antisemitism or Islamophobia.

\section{REFERENCES}

- Alshammari, Dalal. 2013. "Islamophobia.", International Journal of Humanities and Social Science 3(15): 177-180.

- Bastian, Brock. 2012. "Immigration, Multiculturalism and the Changing Face of Australia." In Peace Psychology in Australia, edited by Diane Bretherton and Nikola Balvin . Boston: Springer.

- Bayrakli, Enes, and Farid Hafez. 2018. "European Islamophobia Report 2017." SETA - Foundation for Political, Economic and Social Research, Istanbul.

- Bleich, Erik. 2012. "Defining and Researching Islamophobia." Review of Middle East Studies 46 (2): 180-189.

- Bloemraad, Irene and Matthew Wright. 2014. "Utter Failure" or Unity out of Diversity? Debating and Evaluating Policies of Multiculturalism." International Migration Review 48 (S1): S294.

- European Network Against Racism. 2017. "Introduction." Accessed November 8, 2019. https:/ / www.enar-eu.org/ Introduction-1156.

- European Union Agency for Fundamental Rights. 2017. "Second European Union Minorities and Discrimination Survey. Muslims - Selected Findings." Publications Office of the European Union. Accessed November 8 2019. https://fra.europa.eu/sites/default/files/fra_uploads/fra-2017-euminorities-survey-muslims-selected-findings_en.pdf. 
- Frunza, Sandu. 2010. "Pluralism si multiculturalism." Journal for the Study of Religions and Ideologies 3 (9): 136-143.

- Hofstede, Geert. 1980. Culture's Consequences: International Differences in Work-related values. London, Sage Publications.

- Housing Europe. 2015. "A State of Housing in the EU 2015. A Housing Europe Review." 5 May. Accessed October 192019. http:/ / www.housingeurope.eu/resource-468/the-state-of-housing-in-theeu-2015.

- Issa, Tozun, Jone Ordono Olabarrieta, Sumi Holingworth, and Sabine Severiens. 2013. "Citizenship education and ethnic and cultural diversity: A scoping study of Sirius network countries on the education of children from a migrant background." December. Accessed October 102019. http://www.sirius-migrationeducation.org/wpcontent/uploads/2013/12/CitizenshipEducationReporttot_SIRIUS_131203.pdf.

- Komurcu, Osman. 2019. "Multiculturalism in the EU and the Islamophobia Case" PhD. diss., National University of Political Studies and Public Administration.

- Kukathas, Chandran. 2004. "Nationalism and Multiculturalism." In Handbook of Political Theory., edited by Gerald Gaus and Chandran Kukathas. London: Sage Publications.

- Kymlicka, Will. 2012. "Multiculturalism: Success, Failure, And The Future." Transatlantic Council on Migration, February.

- Modood, Tariq. 2005. Multicultural Politics: Racism, Ethnicity and Muslims in Britain. Edinburgh: Edinburgh University Press.

- Open Society Institute. 2011. "Muslims in Europe. A report on 11 EU cities." $2^{\text {nd }}$ edition, Hungary, Accessed October 72019. https://www.opensocietyfoundations.org/uploads/8dfc7811-b0e1-4b409ca4-35593a65274b/a-muslims-europe-20110214_0.pdf.

- Salat, Levente. 2001. Multiculturalismul liberal. Bazele normative ale existentei minoritare autentice, Bucuresti: Polirom. 
- Sirovatka, Tomas. 2011. "Promoting Social Inclusion of Roma. A Study of National Policies." European Commission, DG Employment, Social Affairs and $\begin{array}{llll}\text { Inclusion. } & \text { Accessed } & \text { September } & 28\end{array}$ ec.europa.eu / social / BlobServlet?docId=8965\&langId=en.

- Tausch, Arno. 2019. "Migration from the Muslim World to the West." Jewish Political Studies Review 30 (1/2): 65-225.

- Triandafyllidou, Anna. 2012. Addressing Cultural, Ethnic and Religious Diversity Challenges in Europe: A Comparative Overview of 15 European Countries. Florence: Robert Schuman Centre for Advanced Studies.

- Turner, Margery Austin. 2015. "Tackling the legacy of neighborhood segregation." Urban Wire, 22 May. Accessed October 8, 2019. https://www.urban.org/urban-wire/tackling-legacy-neighborhoodsegregation.

- Wieviorka, Michel. 1991. L'espace du racism, Paris: Edition du Seuil. 